\author{
OHS ACADEMY \\ $\dot{I}_{S ̧}$ Să̆gl $\breve{g} l$ ve Güvenliği Akademi Dergisi \\ Açı Erişim \\ Journal of Occupational Health and Safety Academy \\ Open Access
}

e-ISSN: 2630-578X

https://doi.org/10.38213/ohsacademy.823716 $\quad$ Y11 2020, Cilt 3, Say1 3, Sayfa: 206-220 https://dergipark.org.tr/tr/pub/ohsacademy

\title{
İşletmelerde İş Sağlığı ve Güvenliğinin İyileştirilmesi Amacıyla Altı Sigma Kalite Yönetim Sistemi ile Model Oluşturulması
}

\author{
Canan Uçan ${ }^{1}$, Ahmet Tuğrul Savaş² \\ ${ }^{1}$ İşletme Bölümü, Lisansüstü Eğitim Enstitüsü, Okan Üniversitesi, İstanbul, Türkiye \\ 2 İşletme Bölümü, Lisansüstü Eğitim Enstitüsü, Okan Üniversitesi, İstanbul, Türkiye
}

$\begin{array}{lr}\text { Makale Tarihçesi } \\ \text { Gönderim: } & 09.11 .2020 \\ \text { Kabul: } & 27.12 .2020 \\ \text { Yayım: } & 31.12 .2020\end{array}$

Araştırma Makalesi
Öz- Altı Sigma Kalite Yönetim Sistemi bir ürünün üretim aşamaları esnasında en az hata ve kayıp vererek üretilmesini ve böylelikle ürünün en az üretim maliyetine sahip olmasını hedefleyen kalite kontrol sistemlerinden biridir. İs Sağlığı ve Güvenliği ise kısaca bir işin yürütülmesi esnasında ortaya çıkabilecek risk ve tehlikeleri en aza indirerek çalışan ve toplum sağlığını korumayı kendine amaç edinmektedir. Bu çalışmada iki senelik bir süreç içerisinde bir işletmedeki İş Sağlığı ve Güvenliği sistemi Altı Sigma Kalite Yönetim Sisteminin enstrümanları ile incelenmiş ve bulunan sorunların Altı Sigma Metodolojisi ile çözümleri önerilmiş ve çözüm önerilerinden uygulamaya koyulanların ne ölçüde iyileştirme getirdiği istatistiksel olarak ortaya koyulmuştur. İlgili çalışmanın tam versiyonu Okan Üniversitesinde Haziran 2019 yllında "'iş SAĞLIĞI ve GÜVENLİĞiNDE ALTI SİGMA YAKLAŞIMI ÜZERINNE BİR MODEL UYGULAMASI" adı ile Doktora Tezi olarak kabul görmüş ve onaylanmıştır.

Anahtar Kelimeler - Altı Sigma, İş Sağlı̆̆ı ve Güvenliği, İş Kazası, Modelleme, Kalite Yönetim Sistemi

\section{Creating a Model with Six Sigma Quality Management System with the Purpose of In- creasing Occupational Health and Safety in Workplaces}

\author{
Canan Uçan ${ }^{1}$, Ahmet Tuğrul Savaş²
}

${ }^{1}$ Business Department, Graduate Institute, Okan University, Istanbul, Turkey

${ }^{2}$ Business Department, Graduate Institute, Okan University, Istanbul, Turkey

\begin{abstract}
Article History
Received: $\quad 09.11 .2020$

Accepted: $\quad 27.12 .2020$

Published: $\quad 31.12 .2020$
\end{abstract}

Research Article
Abstract - The Six Sigma Quality Management System is one of the quality control systems that aims to produce a product with the minimum flaw and defect during the production processes, and thus the product has the lowest production cost. Occupational Health and Safety aims to protect the health of employees and society by minimizing the risks and dangers that may arise during the execution of a business. In this study, the Occupational Health and Safety system in an enterprise was examined with the instruments of the Six Sigma Quality Management System in a two-year period, and the solutions of the found problems were suggested with the Six Sigma Methodology, and it has been demonstrated statistically to what extent the solutions applied from the solution suggestions provide improvement. The full version of the relevant study was accepted and approved as a Doctorate Thesis in Okan University in June 2019 with the name "APPLICATION OF A MODEL ON SIX SIGMA APPROACHES IN OCCUPATIONAL HEALTH AND SAFETY".

Keywords - Six Sigma, Occupational Health and Safety, Occupational Accident, Modeling, Quality Management System

\footnotetext{
1 cananucan85@gmail.com (D) 0000-0001-8410-7398

2 tugrulsavas@gmail.com (D) 0000-0001-6783-223X
} 


\section{Giriş}

Altı Sigma (6б) Kalite Yönetim Sistemi 1981 yılında ortaya çıkmış ve kısaca bir ürünün üretimi esnasında en az hata ve kayıp ile çalışılmasını böylelikle üretim maliyetinin en aza indirilmesini ve son kullanıcıya en kaliteli ürünün en az fiyata ulaştırılmasını sağlamaya hedefler.

Sigma( $\sigma)$ Yunan Alfabesinde bir harf olmanın yanında İstatistik Biliminde de Standart Sapmayı belirtmek için kullanılır. $6 \sigma$ ise istatistiksel bir kütlenin ortalaması ile altı standart sapma kadar uzakta olan bir sınırın arasında kalan alanı ve dolayısıyla o alanın kütlesini belirtmek için kullanılır. Kalite Yönetim Sistemi olarak bakıldı̆̆ında ise bir ürünün kabul edilebilecek özelliklerinin belirli sınırlar içerisinde kaldığı düşünüldüğünde, üretim sonucunda ürünün ortalama değeri ile altı standart sapma uzaktaki ürünün değerinin kabul edilebilir sınırlar içerisinde kalmasını hedefler.

Örnekleyecek olursak bir ekmek firınında 600gr.'llk ekmeklerin üretilmesi hedeflensin. İşletmenin ve kamunun belirlediği kurallar nedeniyle üretilen her bir ekmek hedeflenen değerden en fazla \%1 oranında farklılık gösterebilecektir. Böylelikle fırında üretilen her bir ekmek için kabul edilen sınırlar 594gr. İle 606gr. arasında olmalidir.

Fırında üretilen ekmeklerin ağırlıkları ölçülerek;

$$
\sigma=\sqrt{\frac{\sum_{i=1}^{n}\left(x_{i}-\bar{x}\right)^{2}}{n}}
$$

Formülü ile üretilen ekmeklerin standart sapması bulunur. Bu formülde $\bar{x}$ ekmeklerin ağırlıkları için aritmetik ortalamayı gösterirken, $\mathrm{x}_{\mathrm{i}}$ her bir ekmeğin ağırlı̆̆ını, $\mathrm{n}$ ise üretilen ekmek sayısını belirtmektedir.

Hesaplamalar sonucunda aritmetik ortalamanın 600gr. ve standart sapmanın 1gr. olduğu bulunursa, $594 \mathrm{gr}=\bar{x} \pm$ $6 \sigma=606 \mathrm{gr}$ olduğundan dolayı üretilen ekmeklerin altı standart sapmaya kadar kabul edilebilir sinırlar içerisinde kaldığg görülecektir.

$6 \sigma$ Kalite Yönetim Sisteminin tam olarak hedeflediği istatistiksel olarak bu sonuç olmakla beraber bu sonuca ulaşmak kolay değildir. Tablo 1'de her bir Sigma değeri için hata sayısı verilmiştir.

\section{Tablo 1. Altı Sigma Hata Sayısı Tablosu}

\begin{tabular}{|c|c|c|}
\hline $\begin{array}{c}\text { Hedeflenen } \boldsymbol{\sigma} \\
\text { Aralığı }\end{array}$ & $\begin{array}{c}\text { Başarı } \\
\text { Oranı }\end{array}$ & $\begin{array}{c}\text { Hata Sayısı } \\
\text { (Milyonda) }\end{array}$ \\
\hline$\pm \mathbf{1 \sigma}$ & 30,8538 & 691462 \\
\hline$\pm \mathbf{2} \boldsymbol{\sigma}$ & 69,1462 & 308538 \\
\hline$\pm \mathbf{3 \sigma}$ & 93,3193 & 66807 \\
\hline$\pm \mathbf{4 \sigma}$ & 99,379 & 6210 \\
\hline$\pm \mathbf{5} \boldsymbol{\sigma}$ & 99,9767 & 233 \\
\hline$\pm \mathbf{6} \boldsymbol{\sigma}$ & 99,99966 & 3,4 \\
\hline
\end{tabular}

Tablo 1'den de görüleceği üzere $6 \sigma$ hedefini tutturmak için milyonda sadece 3,4 hata yapılması gerekmektedir. Örnek üzerinden düşünüldüğünde bir firında üretilmesi hedeflenen bir milyon adet 600 gr.'llk ekmeklerden sadece 3,4'ünün kabul edilebilir sınırlar olan 594gr. ile 606gr. aralığının dışında kalması gerekmektedir.

Sonuç olarak $6 \sigma$ hata miktarının istatistiksel ölçümüdür ve hedeflenen bir hata seviyesine ulaşılabilmek adına hataların analiz edilerek tekrar edilmemesinin amaçlandığı, sonuç odaklı iyileştirmelerin önerildiği toplam kalite yönetiminin ismi ve sloganıdır. 


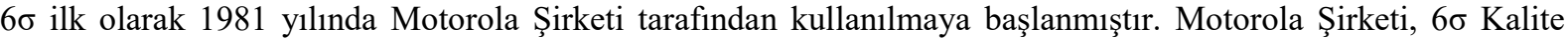
Yönetim Sistemi içerisine DMAIC (Define, Measure, Analyse, Improve, Control-Tanımla, Ölç, Analiz Et, İyileştir, Kontrol Et) adlı modeli oluşturmuş ve üretim aşamalarını bu modelle yönetmişlerdir.

$6 \sigma$ ile alakalı birçok tanım ve anlayış bulunmakla beraber bazı tanımlamalar şu şekildedir.

Japon endüstrisinin İkinci Dünya Savaşından sonra gösterdiği büyük yükselişin arkasındaki felsefe de Deming'in üretim süreçlerinde değişkenliklerin analiz edilerek minimize edilmesi anlayışı olup ve bu yaklaşım aynı zamanda 6 sigmanın temel amacıdır (Atmaca ve Girenes,2009:112-113).

Altı Sigma yaklaşımı, organizasyonlarda maliyetleri düşürmek, verimliliği artırmak ve müşteri memnuniyetini sağlamak, başarı sağlanmadığı her alanda kullanılabilir (Satı ve Gülay,2012:144).

Altı Sigma müşteri ihtiyaçlarını doğru bir şekilde incelenmesi, gerçeklerin, verilerin ve istatistiksel analizlerin anlaşılıp ve doğru bir yerde disiplinli ve sürekli olarak kullanılması ile çalışma süreçlerinin tekrardan gözden geçirilmesine ve iyileştirilmesine yardımcı olur (Pande vd., 2000: xi).

Bir diğer tanım ise, “Altı Sigma sıkı çalışma anlamına gelmez, fakat süreçleri daha akıllıcı ve doğru adımları ve stratejileri atmaya yönelik şekillendirir (Wyper ve Harison, 2000: 722).

The Financial Times (1997), ürünler ve hizmetler çıktısında hataların en aza ve elenmesine amaçlayan bir yöntem olarak tanımlamış (Hahn vd.,1999:2).

Bir diğer tanıma göre Altı Sigma bir araç değil, bir sonuçtur (Wilson, 1999:181).

Altı Sigma kurumların tüm çalışan grupların performanslarını (müşterileri, çalışanları, tedarikçileri, sahipler vb.) memnuniyet yaratarak ve gerekli ihtiyaçlarını temin ederek tüm faaliyetleri içermektedir (Lagrosen ve Lagrosen, 2000: 940).

Yukarıda belirtilenler ışı̆̆ında $6 \sigma$ Kalite Yönetim Sisteminin hedefleri;

- $\quad$ Minimum Hata,

- Üretim Maliyetinin Azaltılması,

- Verimlilik Artış1,

- $\quad$ İş Süreçlerinde Kısalma,

- İş Kazalarında Azalma,

- $\quad$ Maliyet Azalmas1,

- $\quad$ Müşteri Memnuniyeti, 
- $\quad$ Pazar Payı Artış1,

- $\quad$ Çalışanda İş Kültürü Gelişimi.

Olarak özetlenebilir.

$6 \sigma$ Kalite Yönetim Sistemi bir takım işidir. Tek başına sonuç elde edilemez, birçok çalışanın aynı hedef doğrultusunda çalışması gerekir. Bu nedenle sistem içerisinde birçok rol tanımlanmıştır.

Altı sigma organizasyonunun hiyerarşik yapılanmasında yer alan unvan ve roller aşağıdaki gibi sıralanabilir (Devecioğlu ve Yücel, 2012:20; Gürsakal, 2005:130):

- Üst kalite konseyi veya liderlik grubu/konseyi,

- Yönetim temsilcisi,

- $\quad$ Kalite şampiyonu (şampiyon veya sponsor),

- Uzman kara (usta siyah) kuşak,

- $\quad$ Kara kuşak,

- $\quad$ Yeşil kuşak (ekip elemanları).

- Sarı kuşak

Kısaca roller ve ünvanlar tanımlanacak olursa;

- $\quad$ Altı sigma uygulamalarına üst yönetim gerekli önemi ve desteği vermezse altı sigma uygulamalarından istenilen başarı elde edilemez. Bundan dolayı özellikle büyük ölçekli işletmelerde altı sigma uygulamaları için, üst kalite konseyinin veya liderlik grubunun (konseyinin) oluşturulması gerekmektedir (Baş, 2003:24).

- $\quad$ Yönetim temsilcisi konseye bağlı olmakla beraber konseyden aldığı yetki ile süreçlerin yönetimini kendi başına üstlenir ve ilgili konularda raporlamayı konseye yapar. (Baş, 2003:25-26):

- Şampiyonlar, her bir iyileştirme sürecinin sahibi olan kişilerdir. Kısaca sorunu bulan, o sorun ile ilgili çalışmayı yapan, eğitim, para, zaman gibi kaynakları talep eden, iyileştirmeyi yapan ve iyileştirme sonunda oluşan faydayı maddi karşıllı̆ı ile raporlayan kişilerdir. (Gürsakal, 2005:131-132):

- Uzman kara kuşakların, örgütsel ve teknik yeterliliği yüksek olup; kara kuşakların sahip olduğu bilgilerin yanı sıra ileri istatistik ve matematik bilgisine, öğretim, proje yönetimi ve iletişim becerisi gibi becerilere de sahip kişilerdir. Uzman kara kuşaklar altı sigma uygulamalarına teknik liderlik yapan kişilerdir (Pyzdek, 2003:29).

- $\quad$ Kara kuşaklar istatistiki bilgilerinin yanında ilgili süreç ile yeterli teknik bilgisi olan ve sürece konu olan tüm eğitimlere katılmış kişilerdir. Üst düzey iyileştirmelerin başında bulunurlar. Süreçte Aktif rol oynarlar. (Baş, 2003:28):

- Yeşil kuşaklar, iyileştirme projelerine destek olan, projelerde genellikle yarı zamanlı olarak çalışan ve diğer kuşaklara göre altı sigma konusunda daha az eğitimli olan kişilerdir (Linderman ve diğerleri, 2003:195).

- Sarı kuşaklar, süreç ve faaliyetlerle ilgili görev ve tecrübesi olan çalışanlar olup; kara kuşak liderliğinde proje hedeflerinin gerçekleştirilmesi için çalışmaktadırlar (Güneyli, 2009:35). 
Tüm roller tanımlanmış olsa dahi bir $6 \sigma$ sürecinin ilerletilmesi için tüm rollere gerek olmayabilir. Genellikle $6 \sigma$ sürecinin ilerletecek olan işletme sürecin sorunsuz olarak ilerletilmesini sağlayacak en az rol ile sistemini sürdürmektedir.

Görüleceği üzere $6 \sigma$ Kalite Yönetim Sisteminin birçok hedefi vardır. Bu hedeflerden bazıları iş sağlığı ve güvenliği ile doğrudan alakalı olmakla beraber diğer hedefleri de iş sağlığı ve güvenliği ile dolaylı olarak ilgilidir.

İSG'nin temel amacı, işyerlerinde iş sağlı̆̆ı ve güvenliğinin sağlanarak, mevcut İSG şartlarının iyileştirilmesi olarak belirtilmiştir. (6331 Sayılı İSG Kanunu).

$\mathrm{Bu}$ şartların iyileştirilmesinde esas olan risklerin ve tehlikelerin en aza indirilmeye çalışılmasıdır. Risk ve tehlikelerin en aza indirilmeye çalışılmasında uygulanan ana sistem ise risk kontrol adımları ile ortaya koyulmaktadır.

Risk kontrol adımları şu şekilde sıralanmıştır;

a) Planlama: Etki büyüklüklerine ve önem derecelerine göre riskleri sıralayarak bu konuda planlama yapılır.

b) Kontrol Tedbirleri: Riskin yok edilmesi veya uygun seviyeye indirilmesi sağlanır. Bu amaçla.

1) Tehlikenin tamamen ortadan kaldırılması,

2) Mümkün değilse daha az tehlikeli ile değiştirilmesi,

3) Riskin kaynağında mücadele edilmesi.

c) Risk kontrol tedbirlerinin uygulanması: Kararlaştırılan tedbirlerin iş ve işlem basamakları, işlemi yapacak kişi ya da işyeri bölümü, sorumlu kişi ya da işyeri bölümü, başlama ve bitiş tarihi ile benzeri bilgileri içeren planlar hazırlanır. Bu planlar işverence uygulamaya konulur.

d) Uygulamaların izlenmesi: Hazırlanan planların uygulama adımları düzenli olarak izlenir, denetlenir ve aksayan yönler tespit edilerek gerekli düzeltici ve önleyici işlemler tamamlanır.

Kontrol önlemlerin için toplu korunma önlemlerine kişisel korunma önlemlerine göre öncelik verilir. Risk yeterli seviyeye inmediyse ilk adımdan tekrar başlanarak risk kabul edilir seviyeye ininceye kadar tekrarlar yapılır. (Risk Değerlendirme Yönetmeliği)

Risk kontrol adımları Planla-Uygula-Kontrol Et-Önlem Al (PUKÖ) şeklinde sloganlaştırılmış̧ır. Bu açıdan bakıldığında $6 \sigma$ ’nın TÖAİK yaklaşımı ile İSG'nin PUKÖ yaklaşımı çok benzer görülmektedir. 


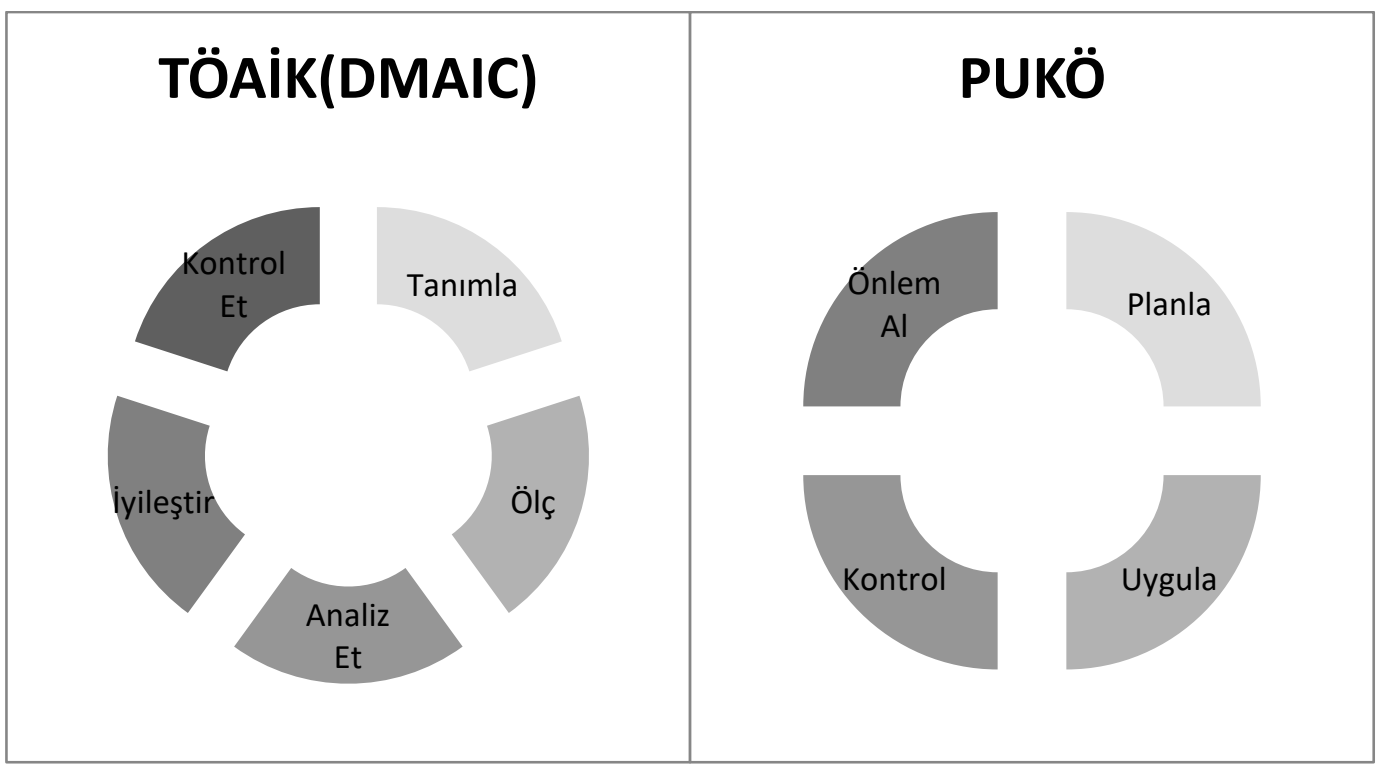

Şekil 1. Altı Sigma DMAİC- İSG PUKO Şeması

Görülmektedir ki her iki yaklaşımında üst yönetimce desteklenmesi ve her bir adımın üzerinde ciddi şekilde çalışılması gerekmektedir. Bu konu $6 \sigma$ için bir gereklilikken İSG açısından yasalarca emredilen bir durumdur.

Tüm bu benzerlikler göstermektedirki İSG Süreçlerinin $6 \sigma$ Yönetim Sistemi ile yönetilmesi mümkündür. Ayrıca Kalite Yönetim Sistemi olarak 6 $\sigma^{\prime}$ yı kullanan işletmelerde bu durum kolaylık da sağlayacaktır.

\section{Gereç ve Yöntem}

Araştırma kapsamında Türkiye'nin Marmara Bölgesinde faaliyet gösteren bir beyaz eşya üretim fabrikası ele alınmıştır.

İlk olarak ilgili fabrikada meydana gelen 2017 yılı içerisindeki tüm iş kazaları incelenmiş̧ir. Meydana gelen kazaların raporlarından hareketle tüm kaza verileri istatistiksel yöntemler ile analiz edilmiştir. Analizler sonucu hipotezler oluşturulmuş ve oluşturulan hipotezler için veri özellikleri ile uygun olan parametrik olmayan ki kare bağımsızlık testi uygulanmıştır.

İkinci olarak ilk bölümün hipotez sonuçlarından yola çıkılarak sorunlu görünen durumlar ve/veya demografik bölümler için $6 \sigma$ metodolojileri ile iyileştirme süreçleri hazırlanmıştır. $6 \sigma$ iyileştirme metodolojileri 2018 yllı boyunca uygulanmıştır.

Son olarak 2018 yılı içerisindeki iş kazası verileri istatistiksel olarak analiz edilerek 2017 yllı kaza istatistiklerinin analizleri ile karşılaştırılmıştır ve $6 \sigma$ iyileştirme metodolojilerinin ne ölçüde iyileştirme sağladığı gösterilmiştir.

Bu bilgiler 1şığında araştırmanın ilk bölümünde Nicel Araştırma Yöntemi kullanılarak mevcut durum ortaya koyulmuş, ikinci bölümünde Nitel Araştırma Yöntemlerinden Uygulamalı Labaratuvar çalışması yöntemi ile iyileştirme metodolojileri geliştirilmiş ve son olarak iyileştirme metodolojilerinin ne ölçüde işe yaradığını görmek amaciyla tekraradan Nicel Araştırma Yöntemlerinden Korelasyon Yöntemine geçilerek sonuç analizleri yapılmıştır.

Araştırmanın makaleye yansıtılan kısmında örnek olması amacıyla sadece çalışanların yaşları ile kaza sayıları arasındaki ilişkiye ait veriler paylaşılmıştır. Hipotezler ve iyileştirme metodolojisi sadece bu veriler üzerinden anlatılacaktır. 


\section{Bulgular-Hipotezler}

İlgili işletmede 2017 yılı içerisinde 3919 kişi çeşitli görevlerde çalışmıştır. Tablo 2.'de çalışanların yaşlarının ait oldukları yaş aralıklarına göre dağılımı verilmiştir.

Tablo 2. 2017 Yılı içerisinde işletmede çalışanların yaş aralıklarının dağılımı

\begin{tabular}{|c|c|c|}
\hline \multicolumn{3}{|c|}{$\begin{array}{c}\text { İşletmedeki tüm çalışanlar için elde } \\
\text { edilen demografik oranlar }\end{array}$} \\
\hline & Çalışan Sayısı & Oran \\
\hline $\mathbf{1 8 - 3 0}$ Yaş & 1177,0 & 0,3 \\
\hline 31-40 Yaş & 1866,0 & 0,476 \\
\hline 41-50 Yaş & 745,0 & 0,19 \\
\hline 51 ve üzeri & 131,0 & 0,0335 \\
\hline Total & 3919,0 & 0,9995 \\
\hline
\end{tabular}

Görüleceği üzere işletmede 2017 yılı içerisinde işletmede çalışanların \%30’u 18-30 yaş aralığında, \%47,6'sı 3140 yaş aralığında, \%19'u 41-50 yaş aralığında ve \%3,35'i ise 51 yaş ve üzeri aralığında bulunmuştur.

$\mathrm{Bu}$ veriden hareketle çalışan yaşları ile kaza sayıları arasında anlamlı bir ilişki olup olmadığı incelenmek üzere Hipotez A kurulmuştur.

Hipotez A: Altı sigma uygulaması öncesinde ortaya çıkan kazalar ile kazaya karışan çalışanın yaşı arasında anlamlı bir ilişki var mıdır?

Eldeki verilerden hareketle uygun analiz yönteminin parametrik olmayan ki-kare bağımsızlık testi olduğu belirlenmiştir. İşletmede 2017yılı içerisinde 69 adet iş kazası rapor edilmiştir ve bu kazalar ile çalışanın ait olduğu yaş aralığı arasında parametrik olmayan ki-kare bağımsızlık testi uygulanmıştır. Elde edilen sonuç Tablo 3'de paylaşılmıştır.

Tablo 3. 2017 Yılı içerisinde işletmede meydana gelen kazalar ile çalışan yaş aralıkları arasındaki parametrik olmayan ki-kare bağımsızlık testi sonuçları

\begin{tabular}{|c|c|c|c|c|c|}
\hline \multicolumn{6}{|c|}{ Yaş Aralıkları-Kaza Sayısı Ki-Kare Bağımsızlık Testi } \\
\hline $\begin{array}{c}\text { Yaş } \\
\text { Dağılımı }\end{array}$ & $\begin{array}{c}\text { Gözlemlenen } \\
\mathrm{N}\end{array}$ & Beklenen N & $\begin{array}{c}\text { Gözlenen-Beklenen } \\
\text { Fark1 }\end{array}$ & $\begin{array}{c}\text { Gözlenen-Beklenen } \\
\text { Farkı (\%) }\end{array}$ & Asymp. Sig. \\
\hline 18-30 Yaş & 30 & 20,7 & 9,3 & 44,86 & - \\
\hline $31-40$ Yaş & 21 & 32,9 & $-11,9$ & 36,09 & 0,021 \\
\hline 41-50 Yaş & 14 & 13,1 & 0,9 & 6,74 & 72,96 \\
\hline 51 ve üzeri & 4 & 2,3 & 1,7 & & \\
\hline Total & 69 & & & & \\
\hline
\end{tabular}

P değeri 0,021 olarak hesaplanmıştır ve bu değer 0,05'in altında bulunmasından dolayı çalışan yaş aralıkları ile kaza sayıları arasında anlamlı bir ilişki olduğu gözlemlenmiş ve Hipotez A kabul edilmiştir. 
Hipotez A'nın kabul edilme sebebinin daha iyi anlaşılması için Şekil 2 İncelenmelidir. Şekil 'den görüleceği üzere yaş aralıkları için beklenen kaza sayıları ile gözlenen kaza sayıları arasında ciddi farklılıklar vardır.

En büyük farklılık beklenenden \%72,96 daha fazla kaza sayısı gözlemlenen 51 yaş ve üzeri aralığıdır. Bu değeri \%44,86 daha fazla kaza sayısı gözlemlenen 18-30 yaş aralığı takip ederken, 31-40 yaş aralığında ise beklenenden \%36,09 daha az kaza gözlenmiştir.

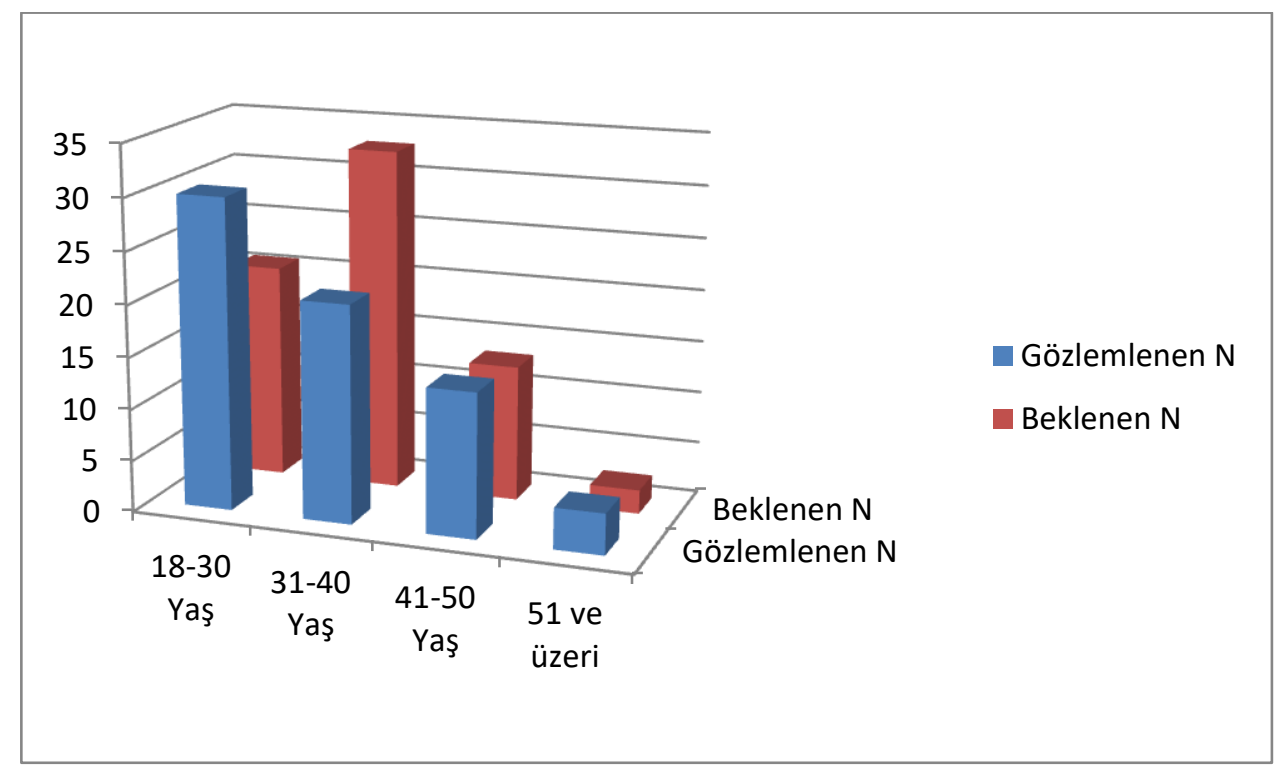

Şekil 2. 2017 yıl için Çalışan Yaş aralıkları için gözlenen-beklenen kaza sayıları grafiği

Şekil 3 üzerinden de anlaşılacağı üzere 1. Yaş aralığı olan 18-30 yaş aralığı ile 4. Yaş aralığı olan 51 yaş ve üzeri yaş aralığı beklentiden çok daha fazla iş kazasına karışmışken, 2. Yaş aralığı olan 31-40 yaş aralığı beklenenden daha az kazaya karışmıştır.

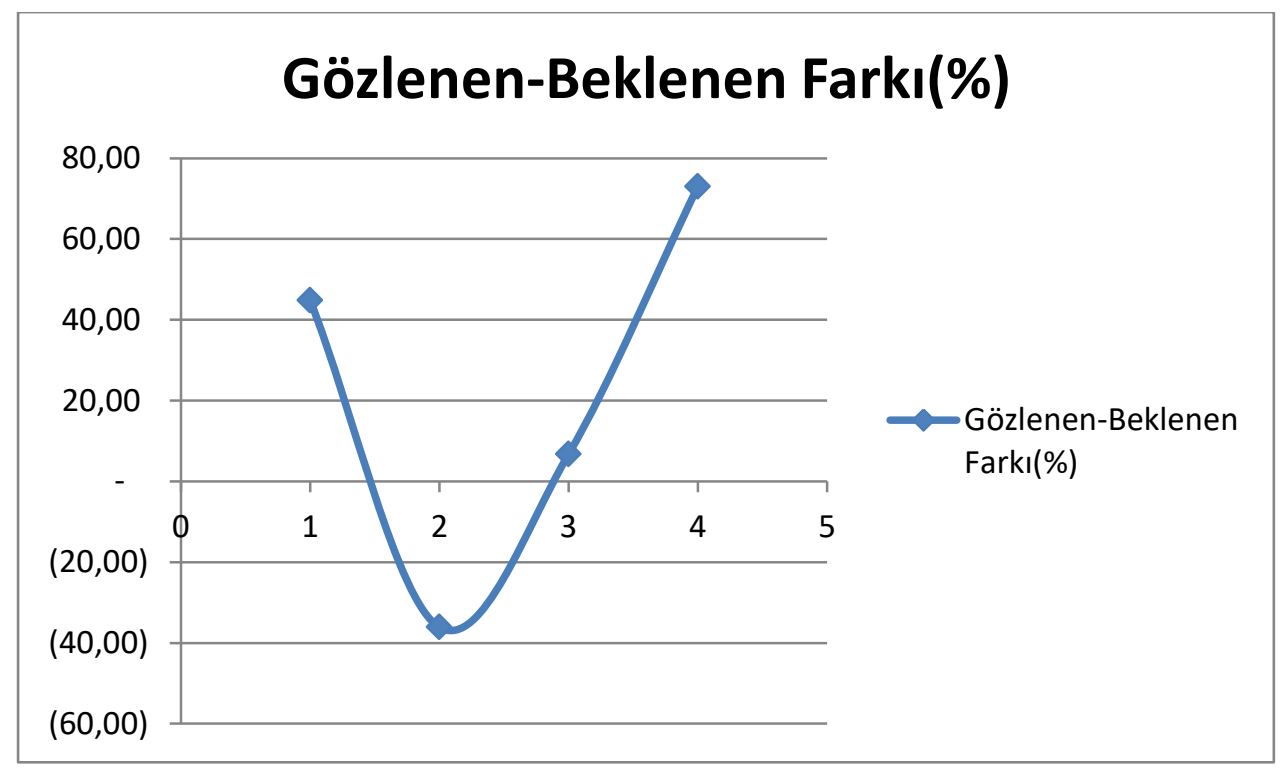

Şekil 3. 2017 yılı için Çalışan Yaş aralıkları için gözlenen-beklenen kaza sayıları farkı grafiği 
$\mathrm{Bu}$ durumda yaş aralıkları ile kaza sayıları arasındaki anlamlı ilişkiyi ortadan kaldırmak için bir adet $6 \sigma$ iyileştirme metodu ortaya konmuştur. Şekil 4'de bu model ayrıntılı olarak belirtilmiş̧ir.

Şekil 4'de görülen modellemeye göre proje sahibi konumunda bulunan kara kuşak altı sigma uzmanı öncelikle kaza verilerini toplamıştır. Kaza verilerini topladıktan sonra verilerin istatistiksel analizini uygun istatistiksel yöntem olan parametrik olmayan ki-kare bağımsızlık testi ile yapılmış ve sorun tanımlanmıştır. Iilgili projede ortaya çıkarılan sorun kaza sayılarının yaş aralıkları ile anlamlı bir ilişkiye sahip olmasıdır. Sorun tanımlandıktan sonra sorun için üretilen iyileştirmeler üretilmiştir. Bu iyileștirmeler ilgili sorun için sorunlu olan yaş aralıklarına normal isg eğitimleri dışında ikişer saat daha eğitim vermek, sorunlu yaş grubundaki personel ile adam başı 10ar dakikalık bire bir ve yüz yüze ek görüşme yaparak sorunun personelce net anlaşıldığını sağlamak ve ilgili risk grubundaki personelikesinlikle riske girmemesi şeklinde uyarmak olarak belirlenmiştir. İlgili iyileştirmeler projeye sponsor olan yönetim kurulu üyesine bildirilmiş̧ir. Sponsor yönetim kurulu üyesi maddi gereksinimi sağlamış ve şirket içerisindeki izinler ile gerekli görevlendirmeler için onay vererek proje sahibi kara kuşak altı sigma uzmanını iyileştirmeler için yetkilendirmiştir. Yetkilenen proje sahibi iyileştirmeleri uygulamak için yeşilkuşak olan İSG Uzmanına ve yapılan iyileştirmelerin sürekli kontrolü için başka bir yeşil kuşak sahibi İSG Uzmanına görev vermiştir. İyileştirmelerin uygulaması ve sürekli kontrolü bir yıl sürmüştür. İyileştirmeler ve süreklikontrolden sonra son bir senelik kaza verileri incelenerek iyileştirmelerin ne ölçüde işe yaradığı proje sponsoru ile istişare edilmiştir. 


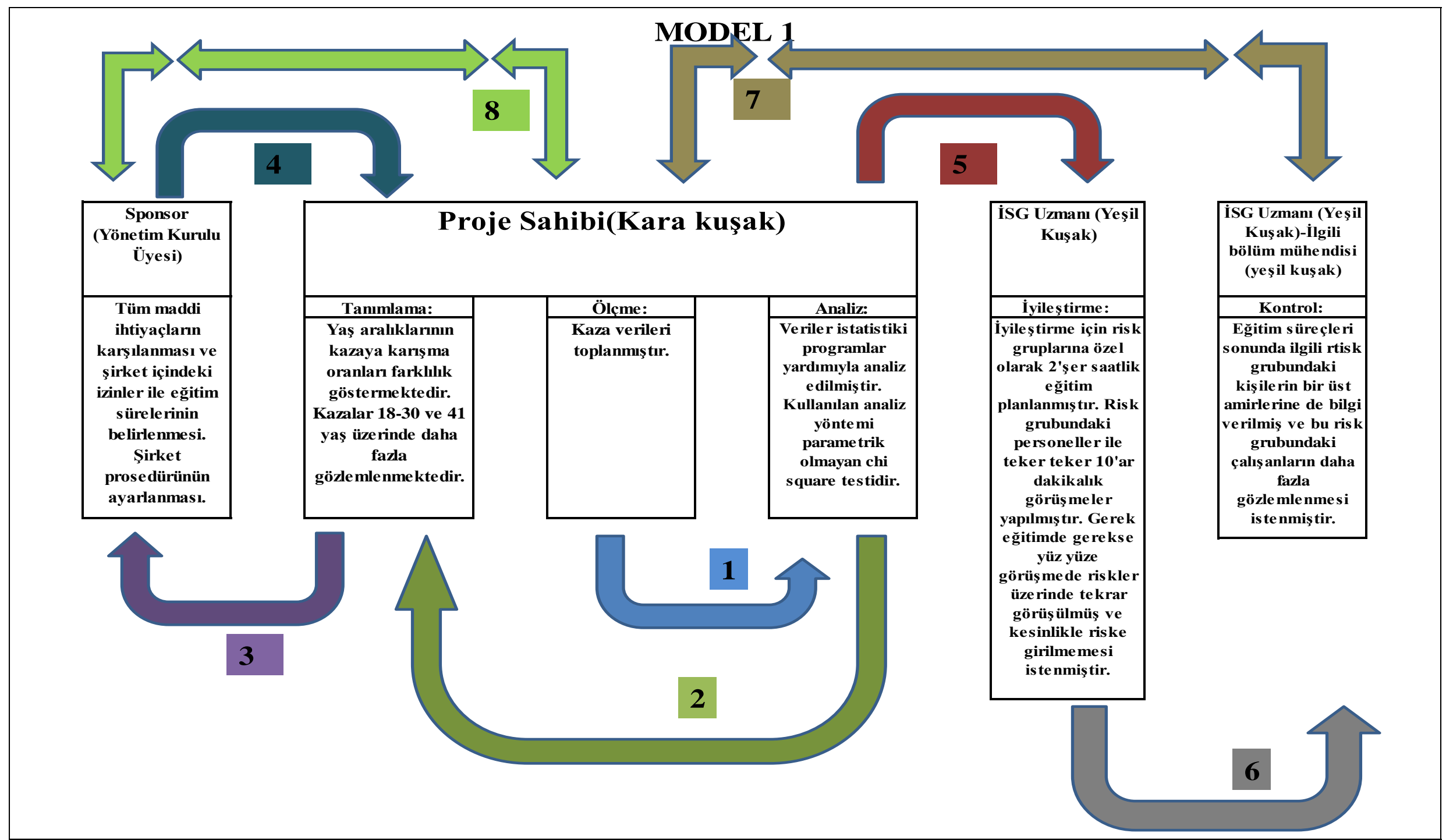

Şekil 4. Model 1 Çalışanlarda Yaş Aralığı-Kaza Sayısı İlişsisinin İyileştirilmesi 
İyileştirmeler sonrasında 2018 yılı kaza verileri incelenmiştir. 2018 yılı içerisinde ilgiliişletmede 4074 kişi çalışmış ve 55 adet iş kazası raporlanmıştır. Tablo 4.'de çalışanların yaşlarının ait oldukları yaş aralıklarına göre dağılımı verilmiştir.

Tablo 4. 2018 Yılı içerisinde işletmede çalışanların yaş aralıklarının dağılımı

\begin{tabular}{|c|c|c|}
\hline \multicolumn{3}{|c|}{$\begin{array}{c}\text { İşletmedeki tüm çalışanlar için elde } \\
\text { edilen demografik oranlar }\end{array}$} \\
\hline & Çalışan Sayısı & Oran \\
\hline 18-30 Yaş & 1222,0 & 0,3 \\
\hline 31-40 Yaş & 1793,0 & 0,44 \\
\hline 41-50 Yaş & 799,0 & 0,196 \\
\hline 51 ve üzeri & 136,0 & 0,0335 \\
\hline Total & 4074,0 & 1 \\
\hline
\end{tabular}

Görüleceği üzere işletmede 2018 yılı içerisinde işletmede çalışanların \%30’u 18-30 yaş aralığında, \%44'ü 31-40 yaş aralığında, \%19,6'sı 41-50 yaş aralığında ve \%3,35'i ise 51 yaş ve üzeri aralığında bulunmuştur.

Bu aşamada altı sigma uygulaması sonrasında ortaya çıkan kazalar ile personel yaş aralıkları arasında anlamlı bir ilişkinin olup olmadığı incelenmesi için Hipotez B kurulmuştur.

Hipotez B: Altı sigma uygulaması öncesinde ortaya çıkan kazalar ile kazaya karışan çalışanın yaşı arasında anlamlı bir ilişki var mıdır?

Kaza sayıları ile yaş aralıkları arasında iyileştirmeler sonrası tekrar parametrik olmayan ki kare bağımsızlık testi yapılmıştır. Tablo 5 de hesaplanan değerler paylaşılmıştır.

Tablo 5. 2018 Yılı içerisinde işletmede meydana gelen kazalar ile çalışan yaş aralıkları arasındaki parametrik olmayan ki-kare bağımsızlık testi sonuçları

\begin{tabular}{|c|c|c|c|c|c|}
\hline \multicolumn{7}{|c|}{ Yaş Aralıkları-Kaza Sayısı Ki-Kare Bă̆ımsızlık Testi } & \multirow{2}{*}{ Asymp. Sig. } \\
\hline $\begin{array}{c}\text { Yaş } \\
\text { Dağılımı }\end{array}$ & $\begin{array}{c}\text { Gözlemlenen } \\
\text { N }\end{array}$ & Beklenen N & $\begin{array}{c}\text { Gözlenen- } \\
\text { Beklenen } \\
\text { Farkı }\end{array}$ & Gözlenen-Beklenen Fark1 (\%) & \\
\hline $\begin{array}{c}18-30 \text { Yaş } \\
\text { Aras1 }\end{array}$ & 23 & 17,0 & 6,0 & 35,14 & \multirow{2}{*}{0,259} \\
\hline $\begin{array}{c}\text { 30-40 Yaş } \\
\text { Arası }\end{array}$ & 19 & 25,0 & $-6,0$ & 23,88 & 7,92 \\
\hline $\begin{array}{c}40-50 \text { Yaş } \\
\text { Aras1 }\end{array}$ & 12 & 11,1 & 0,9 & - & \\
\hline $\begin{array}{c}50 \text { Yaş } \\
\text { Üzeri }\end{array}$ & 1 & 1,9 & $-0,9$ & & \\
\hline Total & 55 & & & & \\
\hline
\end{tabular}

Tablo 5'den de görülebileceği üzere iyileştirmeler sonucunda 2018 yılı için yaş aralıkları ile kaza sayıları arasında yapılan parametrik olmayan ki-kare bağımsızlık testi sonucu 0,259 olarak hesaplanmıştır. Hesaplanan P değerinin 0,05'in üstünde olmasından dolayı Hipotez B ret edilir.

Altı sigma iyileştirmeleri sonucunda 2018 yılında yaşanan kazalar ile personelin yaş aralıkları arasında anlamlı bir ilişki bulunamamıştır. 
Hipotez B'nin ret edilmesinin daha iyi anlaşılması için Şekil 5 ve Şekil 6 incelenmelidir. Şekil 5 'den görüleceği üzere yaş aralıkları için beklenen kaza sayıları ile gözlenen kaza sayıları arasında eskisi kadar ciddi farklılıklar bulunmamaktadir.

Yine en büyük farklılık 51 yaş ve üzeri aralığı olurken bu sefer beklenenden $\% 47,38$ daha az kaza sayısı gözlemlenmiştir. Bu değeri \%35,14 daha fazla kaza sayısı gözlemlenen 18-30 yaş aralığı takip ederken, 31-40 yaş aralığında ise beklenenden \%23,08 daha az kaza gözlenmiştir. Görüleceği üzere yapılan iyileştirmeler sonucunda 51 yaş ve üzeri yaş grubu artık kazaya beklenenden daha az karışmaktadır. 18-30 yaş ise hala beklenenden daha fazla kazaya karışsa dahi bu oran ciddi ölçüde düşürülmüştür.

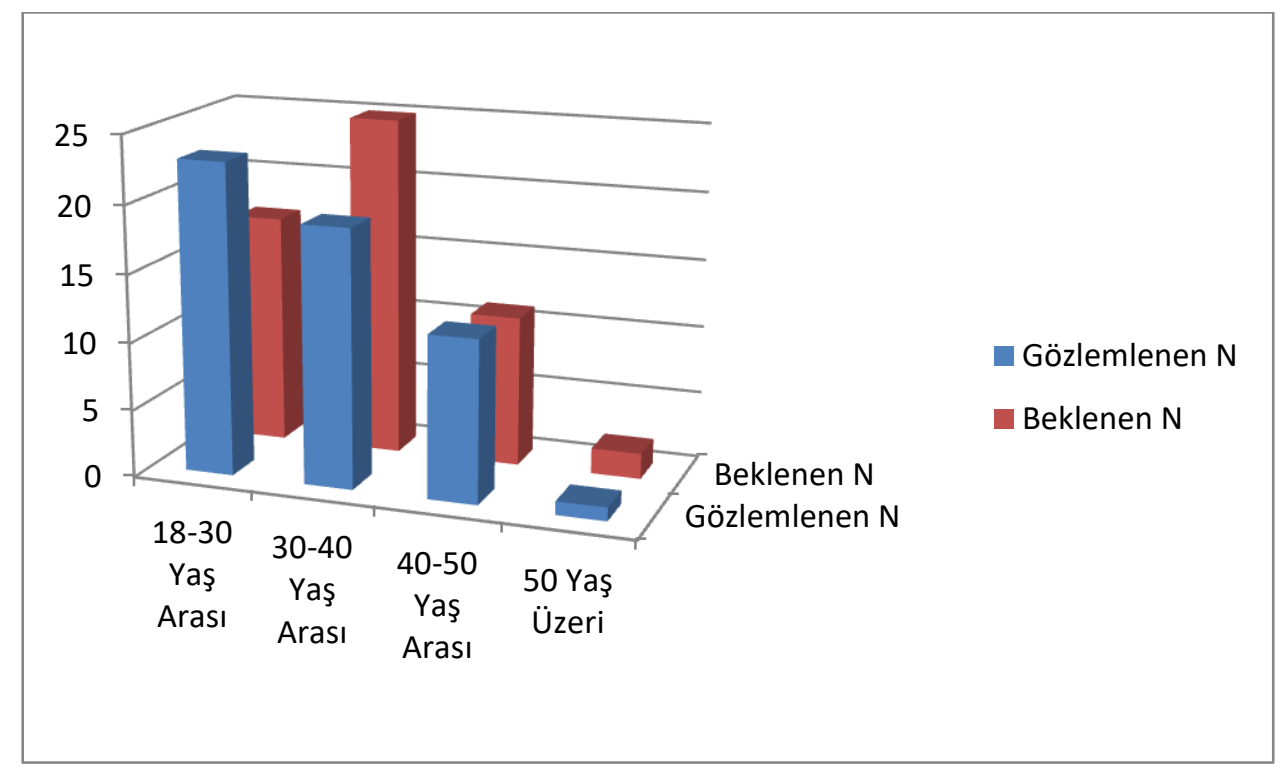

Şekil 5. 2018 yılı için Çalışan Yaş aralıkları için gözlenen-beklenen kaza sayıları grafiği 


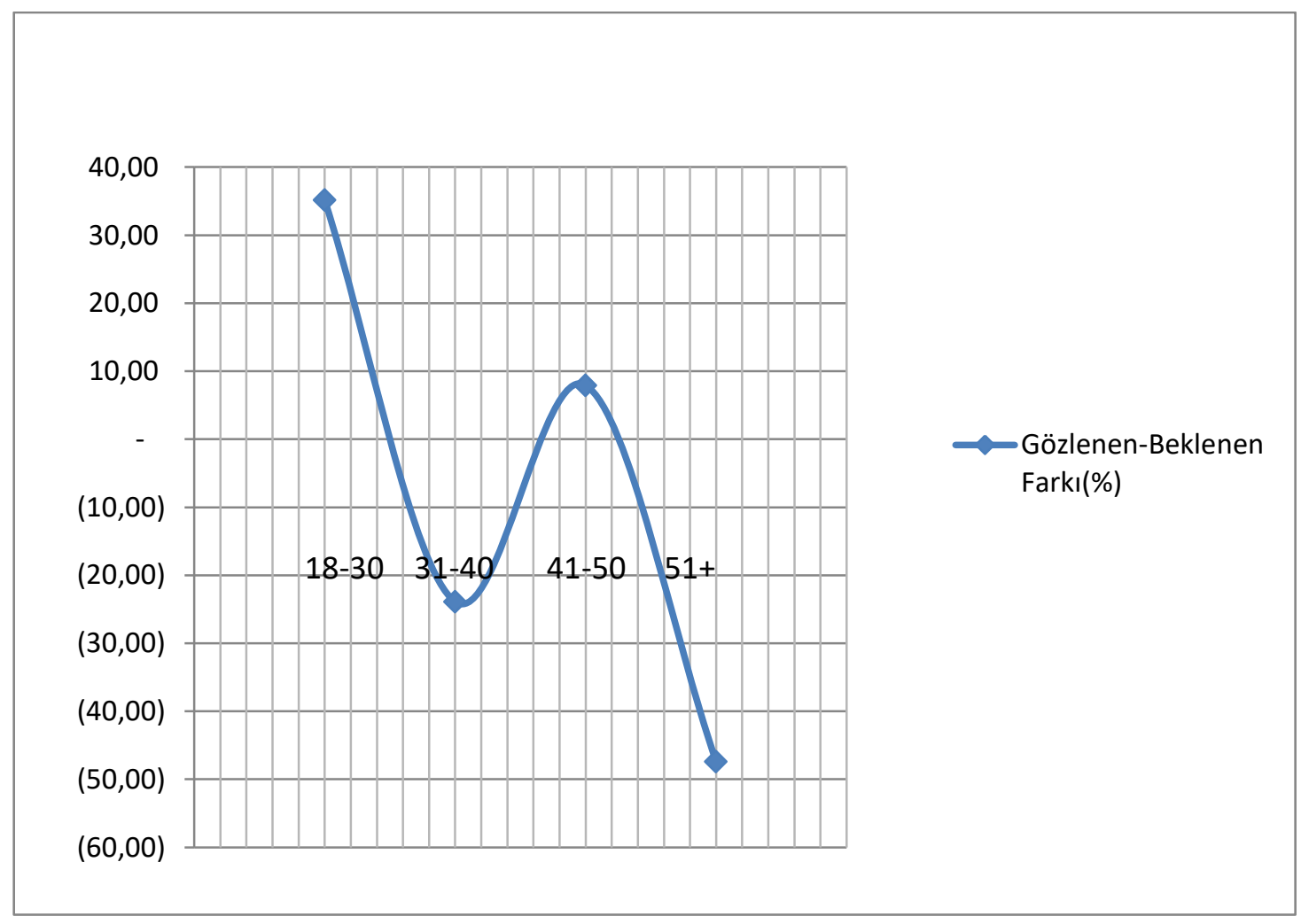

Şekil 6. 2017 yılı için Çalışan Yaş aralıkları için gözlenen-beklenen kaza sayıları farkı grafiği

İyileştirmelerin daha iyi anlaşılması için 2017 yılı ve 2018 yılı gözlenen beklenen farklılıkları grafiği üst üste bindirilerek Şekil 7 de sunulmuştur.

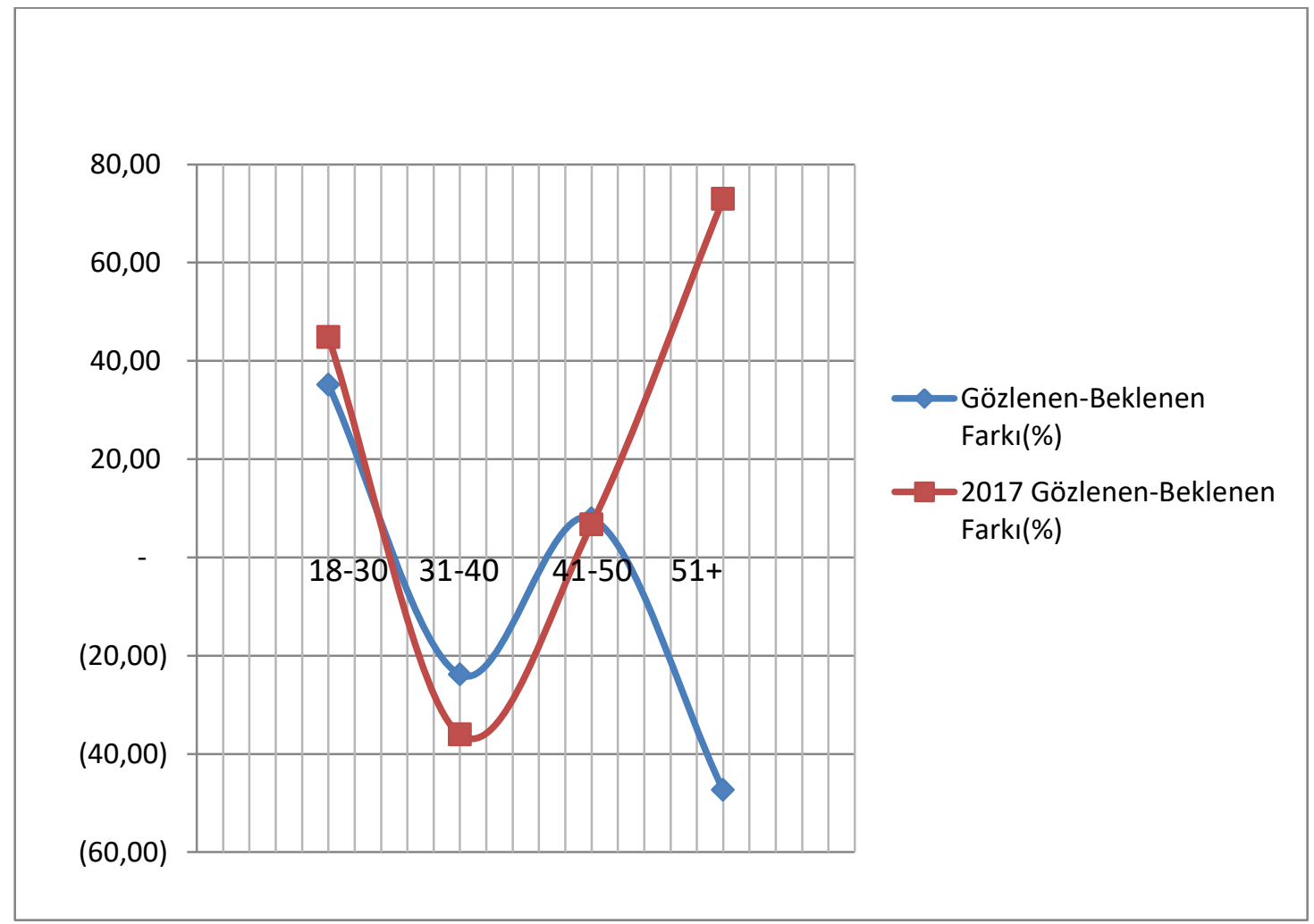

Şekil 7. 2017 ve 2018 yılları için Çalışan Yaş aralıkları için gözlenen-beklenen kaza sayıları farkı grafiği 
Şekil 7'den de anlaşılacağı üzere 18-30 yaş aralığı için 2017 yılındaki beklenen gözlenen farkı olan \%44,86'1 2018 yılında \%35,14'e indirilmiş̧tir. 51 yaş ve üzeri aralığı için ise bu oran \%72,96'dan negatif yönde \%47,38'e muazzam bir başarı ile indirilmiştir.

Gereç ve Yöntemde belirtildiği üzere analizler, hipotezler ve iyileştirme metotları makale kapsamında sadece yaş aralıkları üzerinden anlatılmıştır. Çalışmanın tümünde ise çalışanların yaş aralıkları, çalışanların kıdem süreleri, çalışanların cinsiyeti, çalışanların medeni durumları, çalışanların pozisyonu, çalışanların eğitim durumları, çalışanın kazada etkilenen vücut bölgesi, çalışan güvensiz ortam-güvensiz hareketi, kaza sebebi, kazanın meydana geldiği işyeri bölümü, kazanın meydana geldiği aylar, kazanın meydana geldiği haftanın günü, kazanın meydana geldiği saatler için analizler yapılmış, hipotezler oluşturulmuş ve gerekli olanları için iyileştirme metotları geliştirilmiştir.

$6 \sigma$ iyileştirmeleri öncesinde, 2017 yılı Ocak-Aralık ayları arasında işletmede meydana gelen 69 kazanın neden olduğu iş kayıpları üzerinden sigma seviyesi ölçümlenmiştir. 3919 çalışan için 2017 yılı içerisinde hedeflenen ve tüm tatil günleri ve fazla çalışmalar çıkarılarak bulunan toplam çalışma süresi 8.888.292 adam/saattir. 69 kazanın neden olduğu kayıp iş saati ise 7960 saat olup kaza nedenli kayıplar çıkarıldığında bulunan toplam çalışma süresi 8.880.332 adam.saattir. Kaza başına kaybedilen çalışma süresi 115,36 saat/kaza iken çalışan başına kaybedilen süre 2,03 adam.saat olarak hesaplanmıştır. Bu durumda yapılan sigma ölçümünden elde edilen sigma seviyesi $3,12 \sigma^{\prime}$ dır.

6б iyileştirmeleri sonrasında, 2018 yılı Ocak-Aralık ayları arasında işletmede meydana gelen 55 kazanın neden olduğu iş kayıpları üzerinden sigma seviyesi ölçümlenmiştir. 4074 çalışan için 2018 yılı içerisinde hedeflenen ve tüm tatil günleri ve fazla çalışmalar çıkarılarak bulunan toplam çalışma süresi 9.129 .834 adam.saattir. 55 kazanın neden olduğu kayıp iş saati 6075 saat olup kaza nedenli kayıplar çıkarıldığında bulunan toplam çalışma süresi 9.123.759 adam/saattir. Kaza başına kaybedilen çalışma süresi 110,45 saat/kaza iken çalışan başına kaybedilen süre 1,49 adam.saat olarak hesaplanmıştır. Bu durumda yapılan sigma ölçümünden elde edilen sigma seviyesi $3,21 \sigma$ 'dır.

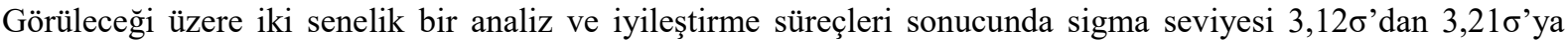
yükseltilmiştir. Lakin hedeflenen sigma seviyesi olan $6 \sigma$ için çok daha fazla çalışılması gereklidir.

\section{Sonuç ve Öneriler}

Araştırmanın makale kapsamında paylaşılan bilgileri ışığında şu sonuçlara varılmıştır.

$6 \sigma$ yönetim sistemi milyonda 3,4 hata oranı ile neredeyse mükemmelliği hedeflemektedir, hedeflenen bu değer ile İş Sağlığı ve Güvenliğinin sıfır kaza hedefi birbiri ile uyumludur. Her iki hedefe de ulaşmış firmalar bulunduğundan dolayı bu hedefler gerçekçi ve sürdürülebilir hedeflerdir.

Çalışma sonuçları göstermektedir ki bir senesi veri toplamakla ve bir senesi de analiz, iyileştirme ve uygulama metodolojileri ile geçen iki senelik bir süreçte dahi kaza sayıları önemli ölçüde düşürülebilmektedir. $6 \sigma$ uygulamaları öncesinde 3919 kişinin çalıştığı işletmede bir sene içerisinde 69 adet kaza olmuşken uygulamalar sonrası 4074 kişinin çalıştı̆̆ işletmede bir sene içerisinde 55 adet kaza olmuştur. Yıl içerisindeki toplam kaza sayıs $\% 20$ civarında azaltılmışı̧ır.

Kaza sayılarının azaltılmasının yanında kaza başına kaybedilen iş süreside azalmıştır. $6 \sigma$ öncesi bir yıl içerisinde 69 kaza ile 7960 saat kaybedilmiştir. Kaza başına kaybedilen süre 115,36 saat/kaza iken çalışan başına kaybedilen süre 2,03 adam.saat olarak hesaplanmıştır. $6 \sigma$ iyileştirmeleri sonucunda bir yıl içerisinde 55 kaza ile 6075 saat kaybedilmiştir. Kaza başına kaybedilen süre 110,45 saat/kaza olurken çalışan başına kaybedilen süre 1,49 adam.saat olarak hesaplanmıştır. Görüleceği üzere $6 \sigma$ iyileştirmeleri sonucunda kaza başına kaybedilen sürede $\% 4,25$ 'lik bir iyileştirme sağlanırken, çalışan başına kaybedilen sürede de $\% 26,6^{\prime}$ 'lı bir iyileşme sağlanmıştır. 
Makale kapsamında paylaşılan verilerden olan yaş aralıklarının kaza sayıları ile ilişkisi incelendiğinde ise görece genç olan (18-30 yaş aralığı) işçiler ile görece yaşlı olan (51 yaş ve üzeri aralığı) işçilerin daha fazla kazaya karıştıkları görülmektedir.

$\mathrm{Bu}$ nedenle işe alım süreçlerinde ve uygun işe yerleştirme süreçlerinde çalışanın yaşı iyi değerlendirilmelidir. Görece genç çalışanların ve görece yaşlı çalışanların daha az risk barındıran işlerde çalıştırılması önerilmektedir.

Ayrıca bu risk grubunda yer alan çalışanlar için ek İSG Eğitimleri planlanarak uygulanması önerilmektedir.

Sonuç olarak İSG bir işletmede birçok farklı bilimsel disiplini kullanarak başarılı olabilmektedir. Özellikle mühendislik ve istatistik bilimleri, iş kazalarının tanımlanması ve önlenmesi açısından çok önemli disiplinler olarak görülmektedir. $6 \sigma$ Yönetim Sistemi birçok farklı disiplini içerisinde barındırarak ölçüm yapan, veri toplayan, verileri analiz eden, sorunu tanımlayan, tanımlanan soruna iyileştirici önerilerde bulunan ve bu iyileştirmeleri uygulayan, süreci sürekli kontrol eden ve iyileştirici süreçlerin başarı olup olmadığını sürekli analiz ederek ölçen yapısı ile İş Sağlığı ve Güvenliğinde yönetim sistemi olarak kullanılabilecek önemli bir sistem olarak önerilmektedir.

\section{Kaynakça}

Atmaca, E. ve Girenes, S.Ş.: (2009), 'Literatür Araştırması: Altı Sigma Metodolojisi' Süleyman Demirel Üniversitesi iktisadi ve idari Bilimler Fakültesi Dergisi. Cilt: 14, Say1:3. 111-126.

Satı, Z.E. ve Gülay, K.: (2012). "Altı Sigma Yönteminin Bir Enerji Santralinde Uygulanması", Business and Economics Research Journal. Volume:3, Num- ber:4. 143-163.

York

Pande, S., P., Neuman, P., R., Cavanagh, R., R.: (2000) 'The Six Sigma Way', McGraw Hill, New

Wyper, B., Harrison, A.: (2000), '’Deployment of Six Sigma Methodology in Human Resource Function: A Case Study, Total Quality Management', July, Volume 11, Issue 4-5, s.720-727

Hahn J., G., William, H., J., Hoerl W., R., Stephan, Z., A., (1999), The Impact of Six Sigma Improvement, The American Statistician, August, Vol 53, No.3, s. 1-8

Wilson, M., P.: (1999), 'Six Sigma Understanding the Concept, Implication and Challenges, Advanced System Consultants'” New York.

Lagrosen, Y., Lagrosen, S.: (2000), 'The Effects of Quality Management a Survey of Swedish Quality Professionals, International Journal of Operations and Production Management', V. 25, N.10, s. 940-952

Devecioğlu, S. ve Yücel. A.S.: (2012). '’Spor Sektörü ve Altı Sigma Yönetim Modeli’’. Spormetre Beden Eğitimi ve Spor Bilimleri Dergisi. 17-24.

Gürsakal, N.: (2005). “Altı Sigma Müşteri Odaklı Yönetim'”. (2.Basım). Ankara: Nobel Yayın Dağıtım.

Baş, T.: (2003).' Altı Sigma',. Kalite Ofisi Yayınları No: 5

Pyzdek, T. (2003). 'The Six Sigma Handbook: A Complete Guide for Green Belts, Black Belts, and Managers at All Levels'. Revised and Expanded Edition. The McGraw-Hill Companies.

Linderman, K., Schroeder, R.G., Zaheer, S. ve Choo, A.S.: (2003). "Six Sigma: A Goal-Theoretic Perspective. Journal of Operations Management', 193-203.

Güneyli, O.: (2009). 'Sağlık Sektöründe Altı Sigma Uygulaması'. Yüksek Lisans Tezi. Kocaeli Üniversitesi. Fen Bilimleri Enstitüsü.

İş Sağlığı ve Güvenliği Kanunun 6331 Sayılı Resmî Gazete Tarih 30.6.2012 Sayı : 28339

İş Sağlığı ve Güvenliği Risk Değerlendirmesi Yönetmeliği Resmî Gazete Tarihi:29.12.2012 Resmî Gazete Sayısı: 28512

\section{Conflict of Interest / Çıkar Çatışması}

Yazarlar tarafından herhangi bir çıkar çatışması beyan edilmemiştir.

No conflict of interest was declared by the authors. 